Aus dem Institut/der Klinik für medizinische Immunologie der Medizinischen Fakultät Charité - Universitätsmedizin Berlin

\title{
DISSERTATION
}

Increased Retention of Gadolinium in the Inflamed Brain after repeated administration of gadopentetate dimeglumine: A Proof-of-Concept Study in Mice Combining ICP-MS and Microand Nano-SR-XRF

zur Erlangung des akademischen Grades

Doctor medicinae (Dr. med.)

vorgelegt der Medizinischen Fakultät

Charité - Universitätsmedizin Berlin

von

Shuangqing Wang

aus China

Datum der Promotion:

18.12.2020 


\section{Tables of Contents}

1. Abstract (English) ….................................................. 1

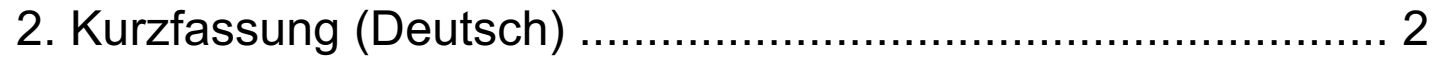

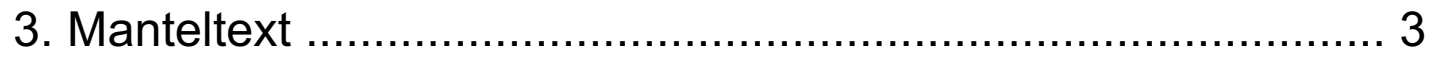

4. Ausführliche Anteilserklärung / eidesstattliche Versicherung...29

5. Auszug aus der Journal Summary List ................................31

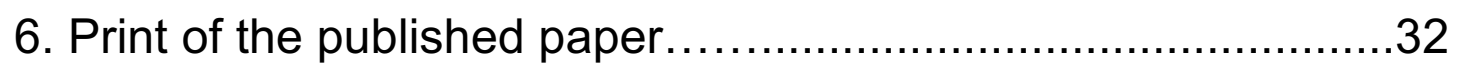

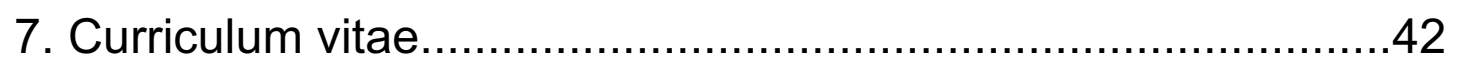

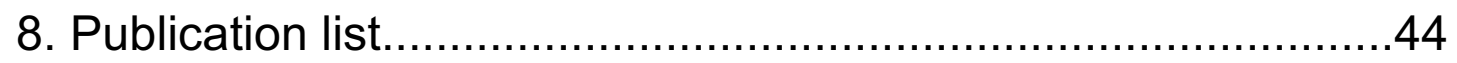

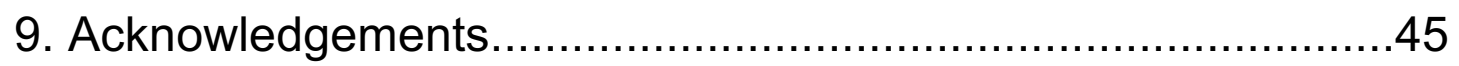




\section{Abstract (English)}

Magnetic resonance imaging (MRI) with gadolinium ( $\mathrm{Gd}$ ) -based contrast agents (GBCA) is used routinely as a diagnostic/prognostic tool in patients with neuroinflammation such as Multiple Sclerosis (MS). However, after multiple applications, GBCA may enter and deposit into the central nervous system (CNS). Here, we used ICP-MS as well as microand nano-synchrotron X-ray fluorescence spectroscopy to detect and quantify $\mathrm{Gd}$ deposition in the brain of experimental autoimmune encephalomyelitis (EAE) mice suffering from neuroinflammation, after repetitive GBCA applications.

Gd deposition in inflamed brains was mapped by SR-XRF one day after the last Gd-DTPA injections, although only mild signal hyperintensity was found on unenhanced T1weighted images. Additionally, using ICP-MS, we detected and quantified $\mathrm{Gd}$ in both healthy and EAE brains, up to ten days after the last injections. However, EAE mouse brains showed higher levels of $\mathrm{Gd}$ (mean $\pm \mathrm{SD}, 5.3 \pm 1.8 \mu \mathrm{g} / \mathrm{g}$; range $4.45-8.03$ ) with respect to healthy controls (mean $\pm S D, 2.4 \pm 0.6 \mu \mathrm{g} / \mathrm{g}$; range, 1.8-3.2). By means of micro SR-XRF, we identified sub-micrometric Gd hotspots in all investigated samples containing up to $5893 \mu \mathrm{g} \mathrm{Gd} / \mathrm{g}$ tissue. Nano SR-XRF further indicated that Gd small hotspots had an average size of $\sim 160 \mathrm{~nm}$ diameter and were located in areas of high inflammatory activity.

Therefore, after repeated administrations of Gd-DTPA, ongoing inflammation may facilitate the retention of $\mathrm{Gd}$ in the brain tissue. Thus, neuroinflammation should be considered as a risk factor in the recommendation on use of linear GBCA-enhanced MRI. 


\section{Kurzfassung (Deutsch)}

Die Magnetresonanztomographie (MRT) in Verbindung mit Kontrastmitteln auf Gadolinium (Gd) -Basis (GBCA) wird routinemäßig als diagnostisches / prognostisches Instrument bei Patienten mit Neuroinflammation wie Multiple Sklerose (MS) eingesetzt. Nach mehrmaliger Anwendung können GBCAs jedoch in das zentrale Nervensystem (ZNS) eindringen und sich dort ablagern. Hier verwendeten wir ICP-MS sowie Mikro- und Nanosynchrotron-Röntgenfluoreszenzspektroskopie, um die Gd-Ablagerung im Gehirn von Experimentellen autoimmune Enzephalomyelitis (EAE) -Mäusen nach wiederholten GBCA-Anwendungen nachzuweisen und zu quantifizieren.Die Gd-Ablagerung in entzündeten Gehirnen wurde einen Tag nach den letzten Gd-DTPA-Injektionen durch SR-XRF abgebildet, obwohl auf nicht verstärkten T1-gewichteten Bildern nur eine milde Signal-Hyperintensität gefunden wurde. Außerdem konnten wir, mithilfe von ICP-MS, bis zu zehn Tage nach den letzten Injektionen $G d$ in gesunden und EAE-Gehirnen nachweisen und quantifizieren. Hier zeigten EAE-Mausgehirne höhere Gd-Werte (Mittelwert $\pm \mathrm{SD}, 5,3 \pm 1,8 \mu \mathrm{g} / \mathrm{g}$; Bereich 4,45 - 8,03) im Vergleich zu gesunden Kontrollen (Mittelwert $\pm \mathrm{SD}, 2,4 \pm 0,6 \mu \mathrm{g} / \mathrm{g}$; Bereich 1,8-3,2). Mit Micro SR-XRF konnte in allen untersuchten Proben submikrometrische Gd-Hotspots mit bis zu $5893 \mu \mathrm{g} \mathrm{Gd} / \mathrm{g}$ Gewebe identifiziert werden. Des Weiteren zeigte Nano-SR-XRF, dass kleine GdHotspots eine durchschnittliche Größe von $160 \mathrm{~nm}$ Durchmesser haben und sich in Bereichen mit hoher Entzündungsaktivität befinden.

Daher kann nach wiederholter Verabreichung von Gd-DTPA eine andauernde Entzündung die Ablagerung von Gd im Gehirngewebe erleichtern. Neuroinflammation sollte daher als Risikofaktor bei der Empfehlung zur Verwendung von linearen GBCAverstärkten MRT betrachtet werden. 


\section{Manteltext}

\section{1) The state of the research}

Multiple sclerosis (MS) is a chronic inflammatory disease of the brain and spinal cord. It is one of the most common cause of non-traumatic disability in young adults, affecting more than two million people worldwide (Thompson, Banwell et al. 2018). MS is considered to be an autoimmune disease in which self-reactive immune cells get access to the CNS leading to myelin destruction, neuroaxonal degeneration and the subsequent formation of multifocal lesions (Weissert 2013). Consequently, the hallmarks of MS pathology are inflammation, demyelination and neurodegeneration (Lublin, Reingold et al. 2014).

Although the exact etiology of the disease is yet unclear, some risk factors that may be involved in MS pathogenesis, includes environmental exposure, genetic susceptibility (Kaminska, Koper et al. 2017), as well as age, gender, family history, race, climate, smoking, vitamin D deficiency, certain infections and autoimmune disease, such as type I diabetes or inflammatory bowel disease (Loken-Amsrud, Lossius et al. 2015). Most patients are often diagnosed between the ages of 20 and 50, with two to three times higher incidence in female than in male (Kurtzke 2005). People living in northern countries, particularly those from Northern Europe, have highest risk of developing MS, while Asian, African and native American people have lowest risk (Mechelli, Annibali et al. 2010). Low level of serum vitamin $D$ increases the risk of developing MS and also affects disease activity in MS patients (Sintzel, Rametta et al. 2018). Besides, Epstein-Barr virus has been linked to MS, as the risk of developing MS following Epstein-Barr virus infections is four times higher after ten years of infection (Steiner, Nisipianu et al. 2001).

There are four main clinical subtypes of MS, clinically isolated syndrome (CIS), relapsingremitting MS (RRMS), secondary progressive MS (SPMS), and primary progressive MS (PPMS). The most frequent forms are RRMS, in which acute attacks are followed by complete or partial recovery, and PPMS, characterized by disease progression from onset. More than $80 \%$ of patients show a relapsing-remitting-course at the beginning of the disease, which in the majority of cases converts to a progressive disease course SPMS - after 10-25 years (Filippi, Preziosa et al. 2016). 
Clinical signs and symptoms of MS are varied and depend on the amount and the location of nerve damage. MS severity is widely measured with the extended disability status scale (EDSS), a score based on symptoms in eight functional systems, walking ability and activities of daily life, including fatigue, walking difficulties, numbness or tingling, spasticity, weakness, vision dysfunctions, dizziness and vertigo, bladder difficulties, sexual troubles, bowel problems, pain, cognitive changes, emotional changes and depression (Green, Cutter et al. 2017, Izquierdo 2017). However, diagnostic methods as the EDSS have limitations, including the small sensitivity in relatively low scores and the lack of the MS lesions activity information.

Therefore, in the last two decades magnetic resonance imaging (MRI) has already become one of the most important and most frequently used imaging tools in the diagnosis and monitoring of MS. In general, T2-weighted MRI is used to determine the MS lesion burden, while active MS lesions can be visualized in vivo by enhanced T1weighted MRI using gadolinium-based contrast agents (GBCA). GBCA-based MRI is used to detect leaky blood-brain barrier (BBB) and white matter lesions, and is commonly used for diagnostic purposes as well as to monitor clinical disease progression and evaluate the patients' response to a given treatment (Geraldes, Ciccarelli et al. 2018).

In general, GBCAs are commonly and widely used to enhance MRI signals to diagnose and monitor different diseases, such as tumor, infection, and bleeding (Goulle, Cattaneo et al. 2009). They have been used for almost three decades and showed a faultless safety record, which profited from the stability depending upon the physicochemical properties. Serious adverse reactions to GBCAs are rare (Hunt, Hartman et al. 2009, Prince, Zhang et al. 2011, Jung, Kang et al. 2012). However, over the past decade, gadolinium (Gd) were shown to be deposited in various tissue after GBCAs applications, including brain (Xia, Davis et al. 2010), bone (White, Gibby et al. 2006), eye (Barker-Griffith, Goldberg et al. 2011), liver, lung, kidney, heart (Sanyal, Marckmann et al. 2011) and skin (Thakral and Abraham 2007). In particular, Gd depositions in the brain tissue cause alarm due to their potential neurotoxicity.

Structurally, GBCAs are categorized into linear agents and macrocyclic agents. Linear GBCAs, such as Magnevist (gadopentetate dimeglumine) and MultiHance, are openchain and less stable, while macrocyclic GBCAs, including Dotarem, Gadavist et al, fully enclose the gadolinium iron. Linear GBCAs were found to lead to enhanced deposits of 
gadolinium in the brain compared to macrocyclic GBCAs (Murata, Gonzalez-Cuyar et al. 2016, Ichikawa, Motosugi et al. 2017). These facts led to suspensions or restrictions on linear agents by the European Medicament Agency (EMA) in November 2017 (EMA/625317/2017) and to the publication of new class warnings and recommendations by the FDA. Particular caution is recommended in case of pregnancy or kidney problems and if patients did already receive the MRIs with GBCAs.

As mentioned above, in central nervous system (CNS), GBCAs are extensively used to diagnose and monitor diseases such as multiple sclerosis that are characterized by alterations in the vascular density and/or permeability. However, Kanda and his colleague first reported high signal intensity appearing in the globus pallidus and dentate nucleus of brain tumors patients who had received multiple MRIs with GBCAs (Kanda, Ishii et al. 2014), and it aroused public concern. It indicated Gd deposition in brain tissue rather than washout after multiple GBCAs applications. Additionally, histological evidences in patients with multiple sclerosis, encephalitis, transient ischemic attack, intracranial hemorrhage and traumatic brain injury (McDonald, McDonald et al. 2015, Stojanov, Aracki-Trenkic et al. 2016) further confirmed this observation.

However, it remains unclear, whether neuroinflammation and BBB disruption may affect the risk of gadolinium retention inside the CNS. In order to further investigate gadolinium deposition in inflamed brain tissue, in our study, we performed multiple Magnevist (linear GBCA) administrations in experimental autoimmune encephalitis (EAE) mice, the prototypical animal model for multiple sclerosis. In addition, we used T1-weighted MRI to image the brain after repeated applications of Magnevist, histology to show the inflammatory areas, inductively coupled plasma mass spectrometry (ICP-MS) to quantify the Gd retention in the brain and synchrotron-based X-ray fluorescence microscopy (SR$\mathrm{XRF}$ ) to map the Gd distribution.

\section{2) In-depth description of the methodology}

\section{1) Experimental autoimmune encephalomyelitis (EAE)}

All interventions related to the in vivo EAE model (induction, scoring, weighting, sacrificing) were conducted by S. Wang. 
The opportunity to obtain CNS tissue from patients is rare, therefore, animal models have been applied to investigate the pathogenesis of the disease. EAE is the prototypical animal model for MS, which is commonly used (Robinson, Harp et al. 2014). Although MS is a uniquely human disease, many histopathological features can be induced in EAE models following induction of CNS-directed autoimmunity, including demyelination, axonal and neuronal damage as well as multiple lesions distributed in time and space. As in MS, lesions are generally perivascular and more prominent in the brain stem and spinal cord (Rangachari and Kuchroo 2013, Baker and Amor 2014). Thus, EAE is an autoimmune, CD4+ T-cell-mediated disease characterized by the breakdown of BBB, mononuclear cell infiltration, demyelination and neurodegeneration (Robinson, Harp et al. 2014).

EAE can be induced in various species, including rodents and primates, by introducing specific antigens, which ultimately result in motor dysfunction. In mice, active EAE can be induced by immunization with specific myelin peptide epitopes (Stromnes and Goverman 2006). Consequently, myelin-specific T lymphocytes are activated in the periphery and migrate across the BBB into the CNS. After entering the CNS, T cells are activated by local and infiltrating antigen-presenting cells, leading to subsequent inflammatory cascades, the involvement of other cells (such as monocytes or macrophages), and ultimately demyelination and axonal damage (Glatigny and Bettelli 2018). On the other hand, passive EAE is induced by the adoptive transfer of encephalitogenic T cells, which were previously obtained from an immunized mouse and activated in vitro.

As in the MS, the disease course can follow a relapsing-remitting form and a chronic form (Figure 1) (Rangachari and Kuchroo 2013). The relapsing-remitting form is normally induced by the immunization of SJL/L mice with proteolipid protein (PLP). This model presents a prominent clinical disability with potential relapse phase and is known to mostly affect cerebellum and to cause a diffuse inflammation. In contrast, the chronic form is commonly induced by the immunization of C57BL/6 mice with myelin oligodendrocyte glycoprotein (MOG), and results in a more pronounced spinal cord pathology (Rangachari and Kuchroo 2013, Bjelobaba, Begovic-Kupresanin et al. 2018). 
relapsing-remitting MS (RRMS)

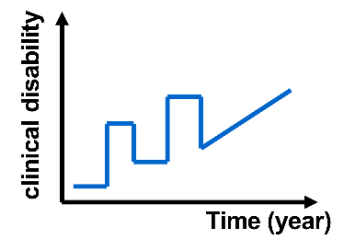

primary-progressing MS (PPMS)

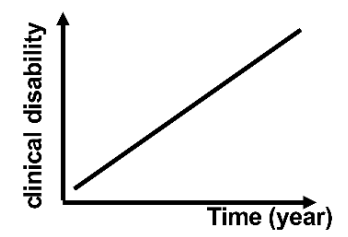

SJL/J mouse (PLP): relapsing-remitting
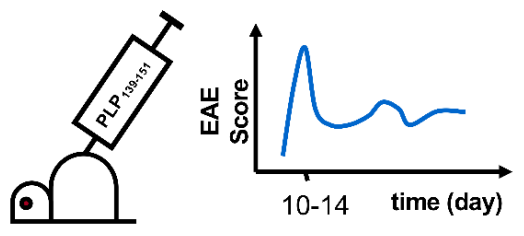

C57BL/6 mouse (MOG): chronic
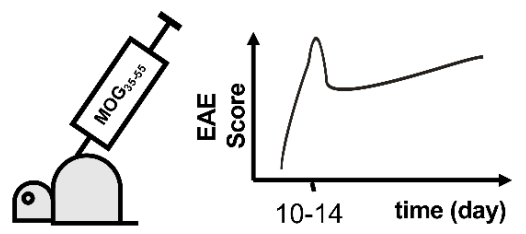

Figure 1. The most frequent forms of MS (left) and EAE (right). In MS patients (left), relapsing-remitting MS (RRMS) presents as acute attacks with following totally or partial recovery and primaryprogressing MS (PPMS) shows a progressing clinic disability. In EAE mouse model (right), the SJL/J mouse is immunized with proteolipid protein $(P L P)$ presenting a relapsing-remitting course, and the C57BL/6 mouse is immunized with myelin oligodendrocyte glycoprotein (MOG) presenting a chronic disease course.

In this study, to better clarify the relationship between inflammation and Gd deposition, EAE was induced by the immunization of SJL/L mice with proteolipid protein (PLP), which presents a typical relapsing-remitting course corresponding to the clinical presentation of RRMS. SJL/L mice were immunized subcutaneously proteolipid protein peptide 139-151 and Mycobacterium tuberculosis H37Ra emulsified in Complete Freund's adjuvant and phosphate-buffered saline. The emulsion provided antigen which initialed expansion and differentiation of PLP-specific autoimmune T cells. The Complete Freund's adjuvant was used to improve the immunogenic potential of the PLP, by activating mononuclear phagocytes inducing the phagocytosis of these molecules and the secretion of cytokines resulting in the prolongation of the presence of antigens and more efficient transport of these to the lymphatic system. Pertussis toxin (PTX) was injected intraperitoneally on the day of immunization and again 2 days later, and it enhanced EAE development by providing additional adjuvant and facilitating entrance of autoimmune T cells into the CNS.

After immunization, mice were monitored daily for clinical signs and recorded in detail as described in Table 1. Clinical signs in EAE are commonly assessed on a six-stage scale of 0 to 5 , with 0 being "clinically normal" and 5 "being died of EAE". To facilitate scoring, 
we also give mice "in-between" scores when the clinical signs lie between two defined score. The" in-between" scores are well established, and help standardized and establishing the final score, principally when signs of disease are mild (between 0 and 2), and thus, difficult to determine. These in-between grades are, however, not included in the publications to facilitate comparison with other labs around the world

Furthermore, clinical signs were scored as follows (s. Table 1): (i) scoring 0 indicates no disease or no obvious changes in motor function compared to non-immunized mice; mice showing mild tail limp paresis (TPA) would be scored as $0.25,0.5$ or 0.75 according to the weakness of the tail, i.e very mild, mild, more severe but not paralyzed, respectively (ii) scoring 1 indicates complete tail paralysis (TPL), or tail paresis (TPA) and affected righting reflex (RRW), simultaneously; mice showing mild hind leg paresis (HPA) would be scored as $1.25,1.5$ or 1.75 according to the weakness of the hind legs, the tail and the righting reflex; (iii) scoring 2 indicates hindlimb paresis (HPA); mice showing dragging of the hind legs would be scored as 2.5; (iv) scoring 3 indicates hindlimb paraplegia; (v) scoring 4 indicates tail paralysis, hindlimb paraplegia and forelimb weakness; the mouse showing moribund or complete hind and partial front limb paralysis without movement would be scored as 4.5; and (vi) scoring 5 indicates death due to EAE.

\begin{tabular}{|c|c|}
\hline Score & EAE clinical signs and records \\
\hline 0 & no clinical signs \\
\hline 0.25 & 0-TPA \\
\hline 0.5 & TPA \\
\hline 0.75 & TPA-L \\
\hline 1 & TPL / TPA + RRW \\
\hline 1.25 & TPA-L + RRW \\
\hline 1.5 & TPL + RRW \\
\hline 1.75 & $0-H P A+$ TPA/ TPL/ RRW \\
\hline 2 & HPA + TPA/ TPL/ RRW \\
\hline 2.5 & HPA-L + TPA/ TPL/ RRW \\
\hline 3 & HPL + TPA/ TPL/ RRW \\
\hline 4 & FPA + TPL + HPL \\
\hline 4.5 & Moribund or TPL + FPL + HPL \\
\hline 5 & dead \\
\hline
\end{tabular}

Table 1. Detailed clinical signs and records of EAE mice. $(T P A=$ Tail paresis. $T P L=$ Tail paraplegia, $R R W=$ Righting Reflex weak, tried $5 x$ into one direction, $H P A=$ Hind limb paresis, HPL = Hind limb paraplegia, $F P A=$ Fore limb paresis, $F P L=$ Fore limb paraplegia) 


\section{2) Applications of GBCA}

Applications of GBCA were conducted by S. Wang.

To investigate whether $\mathrm{Gd}$ deposition is influenced by brain inflammation, healthy control $(\mathrm{HC})$ and EAE mice were exposed for a total of eight applications of a linear GBCA (GdDTPA, Magnevist, Bayer, Germany). GBCA was applied into the tail vein at $2.5 \mathrm{mmol} / \mathrm{kg}$ during four consecutive days, followed by a two-days pause and four additional consecutive daily injections. In total each mouse was injected with a cumulated dose of $20 \mathrm{mmol} / \mathrm{kg}$ Magnevist.

Vasodilation of the tail vein was induced by submerging the tail in warm water for 5 to 10 minutes. Afterward, the intravenous injection of Magnevist was performed with the mouse placed in a sternal position on an appropriate mouse restraining device. The tail was firstly wiped with gauze dampened with $75 \%$ ethanol solution to increase the visibility of the vein and to locate one of the two lateral veins in the middle of the tail. A 27-gauge needle with the bevel facing upward was slid into the tail vein at an angle of approximately $30^{\circ}$. Proper placement of the needle was confirmed by observing a flashback of the blood when applying negative pressure to the plunger. After slowly injecting Magnevist solution through the tail vein, the needle was removed, and the puncture site was gently pressed with a dry piece of gauze until the bleeding stopped. The tail was finally cleaned with disinfectant. When consecutive multiple intravenous injections were needed, strict disinfection procedure and anti-inflammatory therapy with infrared lamp illumination were performed after injection to avoid infection and inflammation of the tail.

In EAE mice, Magnevist application started on day 14 post immunization (p.i.), when EAE mice reached the maximal clinical disability. As depicted in Figure 2, the degree of $\mathrm{Gd}$ retention was investigated in vivo using MRI (s. paragraph 2.3). In addition, Gd quantification and location within the CNS was assessed by ICP-MS (s. paragraph 2.6) and SR-XRF (s. paragraph 2.7), respectively. 

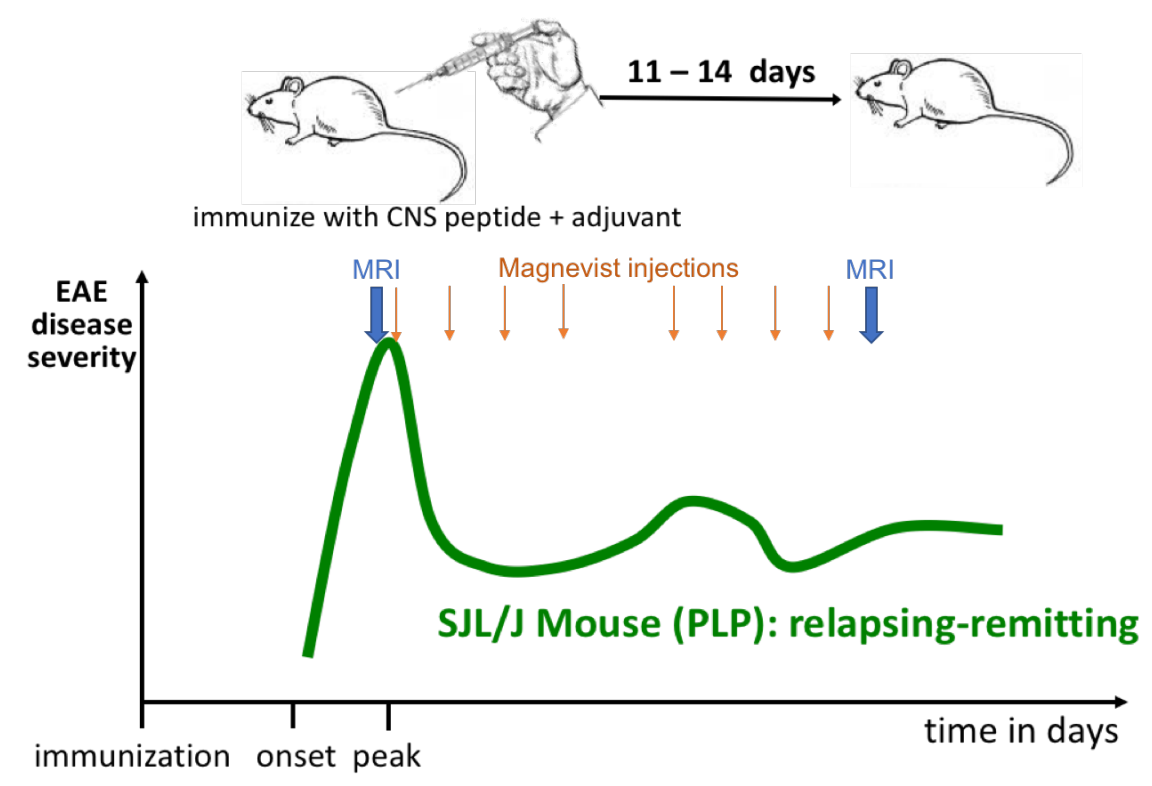

Figure 2. Relapsing-remitting EAE immunized on SJL/L mice and the course of EAE. Mice were performed totally eight Magnevist injections (red arrows), as well as MRIs (blue arrows) before and after injections.

\section{3) Magnetic resonance imaging (MRI)}

MRI scans and analysis were conducted by S. Wang.

MRI is a non-invasive and painless technique that utilizes a powerful magnet and computer-generated radio waves to produce detailed and cross-sectional images of tissues, organs and bones of the body. Unlike X-rays and computed tomography (CT), MRI scans have no damaging ionizing radiation of X-rays. It is a common medical technology to improve the diagnosis and monitoring of diseases including blood vessel damage, brain injury, heart disease, bone infection, damage to joints and tumor in various organs (Ibrahim and Dublin 2018).

MRI uses the principle of nuclear magnetic resonance (NMR) phenomenon to detect the emitted electromagnetic waves through a gradient magnetic field based on the different attenuation of the released energy in different structural environments inside the material. And it provides information about the position and type of nucleus that constitutes this object, which can be used to draw a structural image of the interior of the object (Stikova 2012). Furthermore, the foundation of the NMR is the interaction of a nuclear spin with an 
external magnetic field, $B_{0}$. The dominant nucleus in MRI is the proton in hydrogen, which interacts with the external field resulting in the precession of the proton spin about the field direction. In addition, the energy of interaction with $B_{0}$ depends on the direction of nuclear moments, so that the minimum energy corresponds to the state in which the moments are parallel to $B_{0}$. As a result, in thermal equilibrium, most of nuclear moments are aligned along the external field. The alignment of magnetic moments gives rise to nonzero magnetization in macroscopic samples of solids, liquids or gases containing a large number of nuclei. The NMR phenomenon is observed when a macroscopic sample in a static magnetic field is irradiated by an oscillating magnetic field with a frequency that equals the frequency of precession (McGowan 2008). Additionally, the MR technique using a combination of $90^{\circ}$ and $180^{\circ}$ radiofrequency (RF) pulses to generate an echo signal is called the spin-echo sequence, which is one of the basic sequences performed in MRI. Spatially encoded signals in MRI are obtained by the repetitive and selective excitations of the nuclear magnetization in targeted area of the object. After each excitation, in the presence of external magnetic field gradients, the NMR signal is sampled multiple times within a short acquisition interval (Gray, Burstein et al. 2008). Figure 3 illustrates the steps of the MRI.

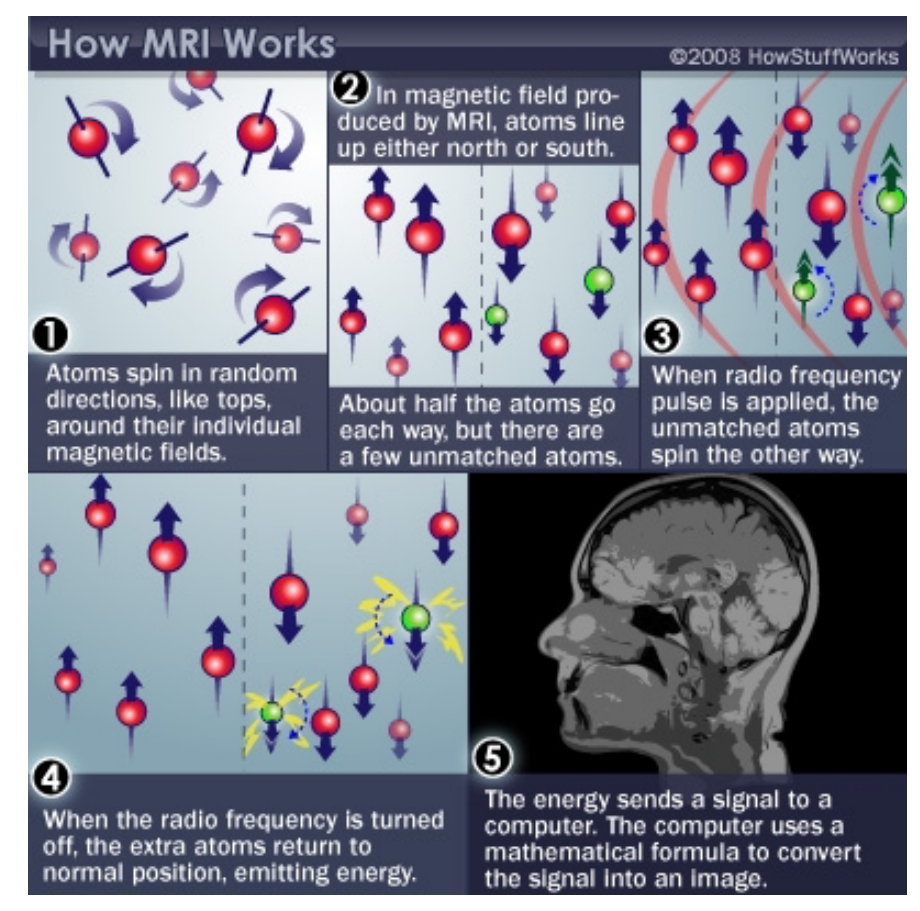

Figure 3. The steps of the MRI. (from: HOWSTUFFWORKS.COM 2008)

The MRI parameters include T1 relaxation and T2 relaxation times, which are intrinsic properties of different tissues (Pooley 2005). The process of realignment to the external 
magnetic field is called the longitudinal relaxation process, and it characterized by the T1 relaxation time. The longitudinal or T1 relaxation time is defined as the time that it takes for the longitudinal magnetization to reach $63 \%$ of its maximum value, assuming a perfect $90^{\circ} \mathrm{RF}$ pulse. Another relaxation process, known as the transverse relaxation, depends on the spins dephasing around the magnetization vector. The transverse or T2 relaxation time is defined as the time that it takes for the transverse magnetization to decrease to $37 \%$ of its original value. In the CNS, white matter, grey matter and cerebrospinal fluid have different T1 and T2 values. White matter has a long T1 and relaxes slowly, and a short T2 and dephases rapidly. Cerebrospinal fluid has a long T1 and relaxes slowly, and a long T2 and dephases slowly. Grey matter has an intermediate T1 and T2 and relaxes at an intermediate rate. Besides, $\mathrm{Gd}$ is sometimes introduced as an intravenous MR contrast medium which leads to a shortening of both longitudinal (T1) and transverse (T2) relaxation with consequent reduction in the $\mathrm{T} 1$ and $\mathrm{T} 2$ values of the tissue in which it accumulates. Gd-induced change in relaxation time presented itself as an increased signal intensity in T1-weighted images and a decreased signal intensity in T2-weighted images. (Panigrahy, Borzage et al. 2010)

As mentioned in the introduction, MRI technique plays a key role in diagnosing and monitoring MS. The presence of CNS lesions brings about signal abnormalities on conventional MRI sequences such as T2 weighted and T2 weighted fluid-attenuated inversion recovery (FLAIR) scans and contrast-enhanced T1 weighted scans. Particularly, the GBCAs-enhanced MRI technique is capable of imaging new MS lesions within the CNS and is routinely used to determine the degree of disease activity. Thus, in the presence of inflammation, GBCA cross BBB, enter the CNS parenchyma, and alter the magnetic properties of the tissue, reducing the $\mathrm{T} 1$ relaxation time. This leakage does not occur when the BBB is intact. In general, the levels of inflammation correlate with the magnitude of GBCA-enhancement on post-contrast T1-weighted scans (Miller, Grossman et al. 1998).

Mouse models of human cerebral diseases are of critical importance in preclinical research. Preclinical MRI ("small animal MRI") for investigating disease development and pathogenesis using small animals such as rodents has been established over the past two decades. Owning to its non-invasive nature, preclinical MRI measurements can be conducted longitudinally, providing anatomical, pathological, and functional information over the course of disease (van de Looij, Vasung et al. 2014). Preclinical MRI has 
demonstrated great potential in assessing neurologic diseases in animal models, providing valuable information to clinical practice. Furthermore, as tissues of animal models are abundantly available for histopathological results, allowing an in-depth investigation of the underling course of diseases.

For small animal MRI, magnets commonly operate at a high field strength, in the range of 4.7 - 11.7 Tesla, as opposed to the standard clinical range of 1.5 - 3 Tesla. The main advantage of the higher field strength is the increased signal-to-noise ratio (SNR), which enables higher resolution acquisition; at the same time, increased image artifacts and limitations related to the specific absorption rate make higher field strength scanning technically more challenging (Denic, Macura et al. 2011). Considering the advantages and limitations, 7-Tesla small-animal scanner is a proper instrument for this study.

Moreover, the MRI sequence should be optimized to obtain images with good resolution and sufficiently SNR under a short acquisition time. All the mentioned parameters (SNR, resolution, acquisition time) are interdependent (van de Looij, Vasung et al. 2014). Given a fixed acquisition time, one could either acquire better spatial resolution (smaller voxel size) at the expense of SNR or reduce spatial resolution in order to gain SNR. In order to keep both high SNR and resolution, longer acquisition might be necessary. Therefore, optimizing the trade-offs between the image quality (SNR and resolution) and acquisition time are considered the primary task when setting up MRI imaging protocols.

In this study, MRI measurements were performed using a 7-Tesla small-animal scanner (Bruker Biospin, Ettlingen, Germany), with a $20 \mathrm{~mm}$ RF quadrature volume head coil (RAPID Biomedical GmbH, Rimpar, Germany) using a T1-weighted 2-dimentional RARE sequence. Scan parameters were as follows: echo time $=11.5$ milliseconds, repetition time $=975$ milliseconds, number of averages $=4$, field of view $=25.6 \mathrm{~mm}^{2}$, number of slices $=32$, number of echoes $=2$, slice thickness $=0.5 \mathrm{~mm}$, scan time $=8$ minutes and 19.2 seconds.

MRI requires that the study subjects to be completely immobilized. In order to achieve this, appropriate anesthesia is required during the scan. Thus, mice were anesthetized via face mask with 1.5-2.0\% isoflurane (Forene, Abbot, Wiesbaden, Germany) in $30 \% \mathrm{O}_{2}$ and $70 \% \mathrm{~N}_{2} \mathrm{O}$, under continuous respiration monitoring using a press-sensitive pad placed in the thorax (Small animal instruction Inc, Stony Brook, NY). Isoflurane 
concentration was adjusted in order to maintain the respiration rate at about 60 breaths per minute (Ewald, Werb et al. 2011). In addition, the core temperature inside narrowbore scanners is $15-20^{\circ} \mathrm{C}$, and a heating system is required to maintain the normal body temperature of mice while in the scanner (Denic, Macura et al. 2011). With the purpose of providing a suitable core temperature, the mice were placed on a bed with circulating heated water to maintain a constant body temperature at $37^{\circ} \mathrm{C}$.

To determine if repetitive application of GBCA leads to retention in the brain, in a group of mice, coronal T1-weighted 2D RARE images were acquired before first Magnevist injection and one day after the last injection. Data acquisition was done with ParaVision 5.1 software (Bruker Biospin, Germany).

\section{4) Mouse perfusion, organ extraction and tissue preparation}

Mouse perfusion, organ extraction and tissue preparation were performed by S. Wang.

Mice were sacrificed either one day or ten days after the last $\mathrm{Gd}$ application. Mice were lethally anaesthetized with $1 \mathrm{ml}$ of a mixture of ketamine $(415 \mathrm{mg} / \mathrm{kg})$ and xylazine $(9.7$ $\mathrm{mg} / \mathrm{kg}$ ). As soon as reflexes between the toes were no longer present, the peritoneum was opened, and the aorta was cut above the diaphragm. To proceed to perfusion, a 25gauge needle attached to a 20-cc syringe that has been filled with PBS was carefully inserted into the left ventricle of the heart. Correct placement of the needle was confirmed by minimal resistance and dark red blood beginning to flow from the right atrium. The animal was then perfused with the entire PBS $(20-30 \mathrm{ml})$.

Thereafter, the brains were carefully taken out and were cut sagittally into two symmetrical halves. Half of the brain was postfixed in $4 \%$ paraformaldehyde overnight at $4^{\circ} \mathrm{C}$ and then PBS washed, following $30 \%$ sucrose in PBS soaking until the tissue sunk to the bottom. Meanwhile, the other half of the brain was stored in liquid nitrogen for elements trace determination (ICP-MS). Hemisphere tissues for histology and SR-XRF were embedded in Tissue Tek Optimal cutting temperature compound and frozen very fast in 2-methylbutane cooled with dry ice, then stored in $-80^{\circ} \mathrm{C}$. Afterwards, those tissue samples were cut horizontally in a cryostat, into $10 \mu \mathrm{m}$ thick consecutive cryosections and stored at $4^{\circ} \mathrm{C}$. In addition, three of the consecutive cryosections from each mouse 
were directly mounted between two ultralene foils (SPEX sample prep) for SR-XRF mapping, descripted below.

\section{5) Hematoxylin and eosin (H\&E) staining}

H\&E staining was performed by S. Wang.

H\&E staining is the most common staining technique in histopathology, with a combination of two dyes, the eosin dye staining cytoplasm and extracellular matrix red or pink and the hematoxylin dye staining nucleus a purplish blue. It is widely used to determine the infiltrating inflammatory cells. In this study, to detect brain regions showing inflammation, frozen hemisphere sections were stained with hematoxylin and eosin.

Frozen hemisphere sections were thawed at room temperature for 30 minutes, then incubated with 4\% PFA (paraformaldehyde) for 10 minutes and shortly rinsed in aqua dest. Afterwards, sections were immersed in Hematoxylin solution for 10 minutes and washed in flowing tap water for 2 minutes. After a short rinse in aqua dest, an incubation of 45 seconds in eosin solution, sections were briefly dunked in tap water and subsequently dehydrated in an ascending ethanol solution $(70 \%, 80 \%, 95 \%, 2 \times 100 \%)$ for 5 minutes each solution, and Neo-Clear solution for 10 minutes, 2 times. Then brain sections were embedded with Neo-Mount solution (Merck, Darmstadt, Germany). Eventually, images were acquired by a Zeiss Axio Observer microscope.

\section{6) Inductively coupled plasma mass spectrometry (ICP-MS)}

The ICP-MS was performed by M. Roman using the brain hemispheres provided by $S$. Wang.

ICP-MS is an analytical technique intended for elemental determinations, which is able to detect elements at very low concentrations with high accuracy. Over the past four decades, it has been established as the most reliable technique for quantifying elements in diversified samples with a wide working range of concentrations and low interferences. ICP-MS enables very sensitive, accurate and precise multi-elemental analysis of trace 
and ultra-trace elements and of isotope ratios. Therefore, it has developed into one of the most important mass spectrometric techniques for studying biological components and environmental materials. (Mittal, Kumar et al. 2017)

ICP-MS consists of an ion source, a sampling interface, an ion lens, a mass spectrophotometer (Balcaen, Bolea-Fernandez et al. 2015). The ion source is an ideal ionization source for mass spectrometry analysis, and it is capable of ionizing over $90 \%$ of many elements. The ions generated in the ion source are introduced into the mass analysis unit through a sampling interface, which is composed of a sampling cone and a skimmer cone. The path of the ions pulled through by the sampling cone and the skimmer cone is focused into the mass spectrophotometer through the ion lens. The ions classified by mass with the mass spectrophotometer are detected by the ion detector. There are many advantages of ICP-MS compared to biomolecular mass spectrometry. In ICP-MS, liquids are generally analyzed directly after dilution, while for biological tissues, the microwave-induced digestion and dilution are required. The atomization, excitation and final ionization of all materials are performed in the ICP ion source. In addition, the atomization and ionization steps are completely separated because they occur in different areas at different times, so that the effect of the matrix on the ionization process can be ignored, and calibration becomes independent of the matrix. (Rodushkin, Engstrom et al. 2013)

Furthermore, ICP-MS has evolved to become a sensitive tool for Gd-specific detection and quantification in various tissues (Frame and Uzgiris 1998, Telgmann, Faber et al. 2012, Sato, Ito et al. 2013, Sato, Tamada et al. 2015). Thus, we chose ICP-MS to identify and quantify the elements, especially $\mathrm{Gd}$, in brain tissues.

In this study, we used ICP-MS to quantify $\mathrm{K}, \mathrm{P}, \mathrm{Na}, \mathrm{Ca}, \mathrm{Fe}$ and $\mathrm{Gd}$ in the hemisphere tissue of four healthy control $(\mathrm{HC})$ and four EAE mice, which were sacrificed either one day $(n=2)$ or ten days $(n=2)$ after the last injection. One hemisphere was selected for each sample, placed into a $2 \mathrm{~mL}$ Eppendorf tube, immediately frozen and shipped to ECSIN Lab. Hemispheres were firstly coded and dried to constant weight in vacuum at $20^{\circ} \mathrm{C}$ overnight, using a Concentrator Plus (Eppendorf) in V-AQ mode. Ten volumes of ultrapure grade concentrated Nitric Acid $\left(\mathrm{HNO}_{3}\right)$ were directly poured into each tube, then samples were placed into a thermostatted block (Falc) at $70^{\circ} \mathrm{C}$ for $8 \mathrm{~h}$ to achieve complete mineralization of the tissue. After cooling, the digests were transferred into $15 \mathrm{ml}$ tubes, 
pooled with triplicate rinse of the original tubes using $1 \mathrm{ml}$ of Milli-Q water each, spiked with the internal standards Sc and Rh, and brought to $10 \mathrm{ml}$ with Milli-Q water (final concentration of $\mathrm{Sc}$ and $\mathrm{Rh} 10 \mathrm{ng} / \mathrm{g}$ ). The solutions were directly analyzed for determination of $\mathrm{K}, \mathrm{P}, \mathrm{Na}, \mathrm{Ca}, \mathrm{Fe}$ and $\mathrm{Gd}$, and further diluted with ultrapure $\mathrm{HNO} 32 \%$ (v/v, plus $10 \mathrm{ng} / \mathrm{g}$ of the internal standards) 1:50 for the determination of Ca and Fe; or 1:1000 for the determination of $\mathrm{K}, \mathrm{P}$ and $\mathrm{Na}$.

Multi-elemental analyses were conducted by ICP-MS using an instrument Agilent 7900 equipped with ASX-500 autosampler (Cetac), glass cyclonic spray chamber thermostatted at $4^{\circ} \mathrm{C}$, quartz torch and $\mathrm{Ni}$ cones. The acquisition was performed in Nogas (for $\mathrm{Na}, \mathrm{Ca}$ and $\mathrm{Gd}$ ) or $\mathrm{He}(4.3 \mathrm{~mL} / \mathrm{min}$, for $\mathrm{K}, \mathrm{P}$ and $\mathrm{Fe}$ ) modes. Instrumental parameters were optimized for best sensitivity in the whole mass range, and minimum oxides (<2.5\%) and double charges (<3\%) levels. Quantification was obtained by external calibration with multi-elemental standards prepared in ultrapure $\mathrm{HNO}_{3} 2 \%(\mathrm{v} / \mathrm{v})$ from the certified level mother solutions ICP-MS calibration standards XXI and V from Analytical Technologies, and IV-Stock-26 from Inorganic Ventures. Three repeated acquisitions were performed for all elements within each analysis.

The wet-to-dry mass ratio of brain samples ranges between 4.1 and 4.5 , consistently with the average value of human brain regions (Krebs, Langkammer et al. 2014). Total mass concentration of $\mathrm{Gd}$ and other elements in the hemisphere sample was reported as a ratio of the dry weight of the hemisphere sample, and the results were reported in the published paper.

\section{7) Synchrotron X-ray fluorescence spectroscopy (SR-XRF)}

S. Wang went to ESRF to image the retention of gadolinium using SR-XRF with the help of Dr. Bernhard Hesse. Analysis of SR-XRF data was mainly performed by B. Hesse. Therefore, the details of analysis were not be include in this manteltext.

X-ray fluorescence spectroscopy is a non-destructive instrumental method of qualitative and quantitative analysis for chemical elements, particularly used in the investigation of metals, glass, ceramics and building materials, as well as in biological tissues, based on the intensities and energies of the emitted X-rays. A synchrotron machine aims to 
accelerate electrons to extremely high energy and then make them change direction periodically. The resulting X-rays are emitted as dozens of thin beams, each directed toward a beamline next to the accelerator. The essential workflow is displayed in Figure 4. SR-XRF is a label free and multi-elemental analyzed method with highly intensive Xrays generated by a synchrotron radiation (SR) excitation source, which can produce $X$ rays 100 billion times brighter than the X-rays used in hospitals. Due to its small source size, low divergence, high photo flux and linear polarization, SR is an ideal source for high-precision XRF analysis of heterogeneous and complex materials. Thus, SR-XRF is capable of focusing on a very small region of interest, and it can be used for mapping with high spatial resolution without destroy the samples, from millimeters to nanometers (Bohic, Cotte et al. 2012).

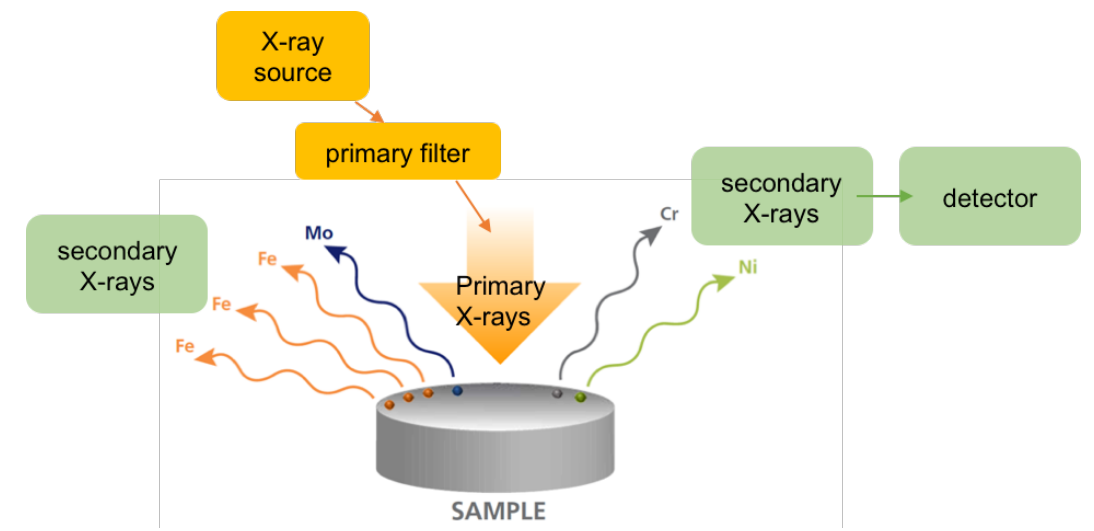

Figure 4. X-ray fluorescence workflow. X-ray source generates the primary $x$-rays, which are modified to $x$-ray beam after through the filter or focusing optics. Secondary $x$-rays are generated by the interaction between the $x$-ray beam and the atoms in the sample, and subsequently collected by a detector, then processed in the analyzer to generate a spectrum showing the $x$-rays intensity peaks versus their energy. (from: Hitachi High-Tech Analytical Science 2019)

In this study, we used SR-XRF to map the distribution pattern of Gd depositions and to reveal potential co-localizations with other elements in the mouse brain. We cooperated with and obtained a grant from the European Synchrotron Radiation Facility (ESRF) in Grenoble, France. ESRF hosts one of the most intense and brilliant hard X-rays sources worldwide, and it is a high energy electron accelerator with an electron energy of 6.02 $\mathrm{GeV}$, giving information about the position and motion of atoms and thus exposing the structure of the tissue. Besides, it is an extremely time-consuming method, and it took around 75 hours in ESRF to obtain the mapping images of eight mouse brains. However, 
each map is composed of many hundred thousand of individual spectra, each spectrum corresponds to one position of the sample.

We performed SR $\mu$ XRF at the ID21 beamline, ESRF (Cotte, Pouyet et al. 2017), which e application aims to identify and localize unknown components in complex mixtures with sub-micrometric resolution and millimetric field of view. The components of ID21 beamline are presented in Figure 5 and includes four complementary end-stations and two separate branch-lines: the direct-branch-line hosts (i) the scanning X-ray microscope optimized for two-dimensional (2D) micro-spectroscopy end-station and (ii) the full-field X-ray absorption end-station. The side-branch-line hosts (iii) the scanning X-ray microscope optimized for 2D micro-X-ray diffraction ( $\mu \mathrm{XRD}$ ) and $\mu \mathrm{XRF}$ end-station; and (iv) the scanning micro-Fourier-transform infrared end-station is independent from the $X$ ray source. In this study we only used the direct-branch-line hosting the scanning X-ray micro-spectroscopy.

The scanning X-ray micro-spectroscopy end-station, exploiting micro fluorescence, operates in the 2.0-9.2 KeV energy range for the acquisition of $2 \mathrm{D} \mu \mathrm{XRF}$ mapping. This energy range gives access not only to low-Z elements (chemical elements with a low atomic number of protons in the nucleus) such as sulfur (S), but also to most of the $3 d$ transition metals such as manganese $(\mathrm{Mn})$, iron (Fe), cobalt (Co), and copper (Cu). Heavier metals such as tin ( $\mathrm{Sn})$, antimony $(\mathrm{Sb})$, lead $(\mathrm{Pb})$ or gadolinium $(\mathrm{Gd})$ can also be analyzed, through their L- or M-edges. It works under vacuum condition; samples are mounted into the scanning X-ray microscope using a transfer chamber and a transfer cane, which allows the main microscope chamber to be kept under vacuum during sample exchange. Besides, a vibration-free cryogenic stage is available for performing cryomicroscopy. Samples can be studied under cryogenic conditions, allowing the study of frozen hydrated biological specimens (cryo-sectioned tissues). It offers the 2D $\mu$ XRF for elemental mapping, and single point micro-X-ray near-edge structure ( $\mu$ XANES) spectra for punctual chemical speciation mapping with sub-micrometric resolution. The beam can be focused down to $\sim 0.3 \mu \mathrm{m}$ (vertical) $\times 0.7 \mu \mathrm{m}$ (horizontal), with a flux of $10^{9}$ to $10^{11} \mathrm{ph} / \mathrm{s}$ by means of Kirkpatrick-Baez mirror system. 


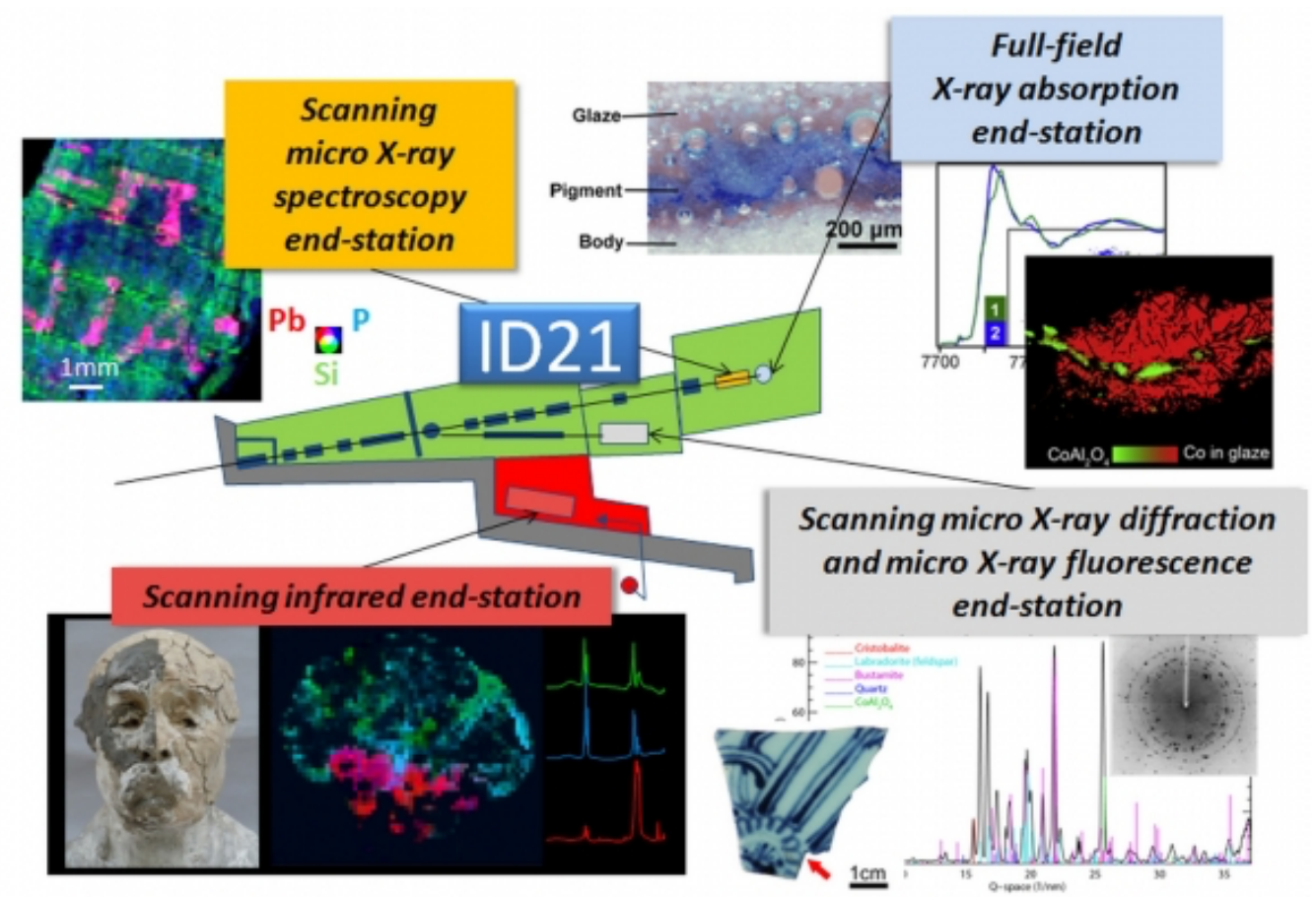

Figure 5. Principle scheme of the ID21 beamline (top view). The ID21 beamline offers four complementary end-stations. The scanning micro-X-ray spectroscopy end-station and the full-field $X$ ray absorption end-station are belonged to the direct-branch-line, while the scanning micro-X-ray diffraction and micro-X-ray fluorescence end-station is belonged to the side-branch-line, and the scanning micro-Fourier-transform infrared end-station is independent from the X-ray source. (from: Synchrotron-based micro-analyses of artistic materials at ID21, ESRF)

To start the experiment, the regions of interest (ROIs) were determined according to the results of MRI scans and H\&E staining performed by $\mathrm{S}$. Wang. Slightly enhanced signal in T1-weight images was found in the cerebellar region of the EAE after multiple GBCA applications, as well as inflammatory lesions notably located in cerebellum. As a result, we choose cerebellar area as the interest region. Then SR $\mu$ XRF maps were performed using the in-vacuum scanning X-ray spectroscopy setup at ID21 beamline, ESRF.

In the beginning of the mapping prior definition of the ROI, Gd L-edge XANES from Gdreference materials was collected. The spectra collected of the $\mathrm{Gd}$ from the brain tissue was then related to this reference values. As reference, we also measured the original contrast agents and the contrast agent in different buffer solutions. To start the SR-XRF, the beamline was optimized for highest possible flux at an energy of $7.3 \mathrm{keV}$. This energy excited the $\mathrm{Gd} L$ lines well, while visualizing the relevant elements $\mathrm{K}, \mathrm{P}, \mathrm{S}, \mathrm{Ca}$ and $\mathrm{Fe}$ in tissue, and its co-localization with $\mathrm{Gd}$ was essential for understanding the distribution of $\mathrm{Gd}$ and the origin of $\mathrm{Gd}$ cluster formation. The beam was focused down to $\sim 0.6 \times 0.8 \mu \mathrm{m}^{2}$ 
(vertical $\times$ horizontal). The flux was $\sim 5 \times 10^{10}$ photons $/ \mathrm{s}(\sim 180 \mathrm{~mA}$ SR current in multibunch mode). Acquisition time per pixel was 100 milliseconds. Afterwards, eight tissue sections from the mouse brain were mounted and investigated, four from healthy mice and four from EAE mice, in two different time points after GBCA applications (1 day or 10 days). For each section, a region of about $4000 \times 4000 \mu \mathrm{m}^{2}$ was scanned at $35 \mu \mathrm{m}$ spatial resolution to allocate the ROI, where subregions were mapped at $10 \mu \mathrm{m}, 3 \mu \mathrm{m}$ and 0.5 $\mu \mathrm{m}$ resolution. In total, each section required around 8-10 hours for the beamline setup, the ROI selection, the sample mounting, and data collection. Following data were mainly analyzed by B. Hesse using PyMCA.

In addition, to better map the Gd distribution in a high resolution, mouse \#3 (M3, EAE mouse sacrificed 10 days after last GBCA application) was analyzed by means of nanoXRF at the ID16B, ESRF (Martinez-Criado, Villanova et al. 2016). This part of study was

performed by $B$. Hesse. The method and analysis details were descripted in the published paper.

\section{3) The significant new results}

We found that after repetitive application of linear GBCA into healthy and EAE mice, Gd deposited more strongly in the inflamed brains.

In addition, using micro- and nano-SR-XRF, we demonstrated that although Gd hotspots were observed in both, healthy and inflamed brains, hotspots were more abundant in the inflamed tissue, particularly inside the cerebellum. Quantification of the total amount of Gd in brains from EAE and healthy mice by ICP-MS confirmed an increased Gd retention in the inflamed CNS.

Thus, inflammation and disrupted BBB may favor Gd retention.

\section{4) The resulting clinical applications and future prospects}

Our results confirmed that after repetitive applications of linear GBCA, Gd is retained in the CNS tissue. Importantly, we show that ongoing inflammation favors the deposition. It 
is known that Gd could bind to other macromolecules (Robert, Fingerhut et al. 2018) via the so-called transmetallation reaction, where $\mathrm{Gd}+3$ is bumped out by another endogenous cation (such as $\mathrm{Zn}+2$ or $\mathrm{Ca}+2$ ). Dissociated free $\mathrm{Gd}+3$ are less stable than chelated Gd in vivo, and they are prone to combine with other endogenous anions (such as phosphate, hydroxide, carbonate or citrate) and deposit in the tissue (Morcos 2008). Those new synthetic and unknown structured chelated $\mathrm{Gd}$ molecules would be continuously accumulating in tissue and highly probably be toxic. In addition, GBCA are extracellular molecules under normal conditions, but the dissociated free $\mathrm{Gd}+3$ which is kicked out by other cations could bind the phosphate acid from the cell wall and get internalized over time (Hao, Ai et al. 2012). Apparently, free gadolinium $(\mathrm{Gd} 3+$ ) is toxic to mammals, but the mechanism of this toxicity is unclear.

Furthermore, a various of short-term symptoms were described related to Gd deposition, called "Gadolinium Deposition Disease", which were observed in both linear and macrocyclic GBCAs (Semelka, Ramalho et al. 2016). These symptoms include tight or sharp pain in the extremities, as well as bone pain, persistent clouded mentation, headaches, and arthralgias (McNamara and Rahmani 2018, Semelka, Ramalho et al. 2018). Those might be the toxic effect of $\mathrm{Gd}$, but not identical, common or severe. Thus, the cause relationship between Gd deposition and chronic effects is not fully recognized, and the side effects of the Gd deposition are still questionable (Tedeschi, Caranci et al. 2017). The clinical and biological significance of deposited gadolinium in the brain remains unknown. There are no signs of harm from gadolinium exposure in animal models, and no behavioral changes have been reported in animals undergoing repeated gadolinium administrations (Robert, Lehericy et al. 2015, Gulani, Calamante et al. 2017).

As motioned, linear GBCAs are less stable than macrocyclic GBCAs and the use of linear GBCAs are now regulated or warned in Europe (EMA) and USA (FDA), but this is not the case for many other countries, e.g. China. Therefore, the use of linear GBCA remains an alarm for the world health. This study should contribute to the worldwide prohibition of linear GBCAs and to encourage the research on potential retention and long-term side effects of the macrocyclic forms of GBCA.

Additionally, in MS, clinical relapses correlate with the development of perivascular inflammatory lesions inside the CNS (Barkhof and Scheltens 2002). Lesion monitoring is commonly required to make an accurate diagnosis and to monitor disease progression 
and response to the treatment. Typically, new lesions are visualized using GBCAs on MRI (Tourbah and Berry 2000). After GBCAs application, gadolinium goes inside the brain through the disrupted blood-brain barrier (BBB) caused by neuroinflammation and the MS lesions are enhanced in the MRI images (Tommasin, Gianni et al. 2017). Generally, the more severe the inflammatory activity, the greater the burden of GBCAenhancement on post-contrast T1-weighted scans (Kaunzner and Gauthier 2017). Therefore, GBCAs enhanced MRI is commonly used for diagnostic purposes and to evaluate the patients' response to a given treatment. Consequently, MS patients are commonly exposed to multiple lifetime doses of contrast agents.

Therefore, a comprehensive risk assessment on the use of linear GBCAs should take into consideration that patients suffering from chronic neuroinflammatory disorders may have an increased risk of gadolinium retention after being exposed to repetitive GBCA applications. Further research is needed to confirm if macrocyclic GBCAs are also increasedly retained in the inflamed brain. More to the point, for future clinic and research, in patients that need GBCAs-MRI, we should obtain the history on possible previous GBCAs administrations and evaluate the need of linear GBCAs administration even more critically than ever. Besides, there is a need to deeply investigate the underlying mechanism of the gadolinium deposition in tissue. To clarify how linear GBCAs deposited in various tissue, and to illuminate the toxicity or side effects of the deposition. 


\section{References}

Baker, D. and S. Amor (2014). "Experimental autoimmune encephalomyelitis is a good model of multiple sclerosis if used wisely." Mult Scler Relat Disord 3(5): 555-564.

Balcaen, L., E. Bolea-Fernandez, M. Resano and F. Vanhaecke (2015). "Inductively coupled plasma - Tandem mass spectrometry (ICP-MS/MS): A powerful and universal tool for the interference-free determination of (ultra)trace elements - A tutorial review." Anal Chim Acta 894: 7-19.

Barker-Griffith, A., J. Goldberg and J. L. Abraham (2011). "Ocular pathologic features and gadolinium deposition in nephrogenic systemic fibrosis." Arch Ophthalmol 129(5): 661-663.

Barkhof, F. and P. Scheltens (2002). "Imaging of white matter lesions." Cerebrovasc Dis 13 Suppl 2: 21-30.

Bjelobaba, I., V. Begovic-Kupresanin, S. Pekovic and I. Lavrnja (2018). "Animal models of multiple sclerosis: Focus on experimental autoimmune encephalomyelitis." J Neurosci Res 96(6): 1021-1042.

Bohic, S., M. Cotte, M. Salome, B. Fayard, M. Kuehbacher, P. Cloetens, G. MartinezCriado, R. Tucoulou and J. Susini (2012). "Biomedical applications of the ESRF synchrotronbased microspectroscopy platform." J Struct Biol 177(2): 248-258.

Cotte, M., E. Pouyet, M. Salome, C. Rivard, W. De Nolf, H. Castillo-Michel, T. Fabris, L. Monico, K. Janssens, T. Wang, P. Sciau, L. Verger, L. Cormier, O. Dargaud, E. Brun, D. Bugnazet, B. Fayard, B. Hesse, A. E. P. Del Real, G. Veronesi, J. Langlois, N. Balcar, Y. Vandenberghe, V. A. Sole, J. Kieffer, R. Barrett, C. Cohen, C. Cornu, R. Baker, E. Gagliardini, E. Papillon and J. Susini (2017). "The ID21 X-ray and infrared microscopy beamline at the ESRF: status and recent applications to artistic materials." Journal of Analytical Atomic Spectrometry 32(3): 477-493.

Denic, A., S. I. Macura, P. Mishra, J. D. Gamez, M. Rodriguez and I. Pirko (2011). "MRI in rodent models of brain disorders." Neurotherapeutics 8(1): 3-18.

Ewald, A. J., Z. Werb and M. Egeblad (2011). "Monitoring of vital signs for long-term survival of mice under anesthesia." Cold Spring Harb Protoc 2011(2): pdb prot5563.

Filippi, M., P. Preziosa and M. A. Rocca (2016). "Multiple sclerosis." Handb Clin Neurol 135: 399-423.

Frame, E. M. and E. E. Uzgiris (1998). "Gadolinium determination in tissue samples by inductively coupled plasma mass spectrometry and inductively coupled plasma atomic emission spectrometry in evaluation of the action of magnetic resonance imaging contrast agents." Analyst 123(4): 675-679.

Geraldes, R., O. Ciccarelli, F. Barkhof, N. De Stefano, C. Enzinger, M. Filippi, M. Hofer, F. Paul, P. Preziosa, A. Rovira, G. C. DeLuca, L. Kappos, T. Yousry, F. Fazekas, J. Frederiksen, C. Gasperini, J. Sastre-Garriga, N. Evangelou, J. Palace and M. s. group (2018). "The current role of MRI in differentiating multiple sclerosis from its imaging mimics." Nat Rev Neurol 14(4): 199-213.

Glatigny, S. and E. Bettelli (2018). "Experimental Autoimmune Encephalomyelitis (EAE) as Animal Models of Multiple Sclerosis (MS)." Cold Spring Harb Perspect Med 8(11).

Goulle, J. P., A. Cattaneo, E. Saussereau, L. Mahieu, M. Guerbet and C. Lacroix (2009). "MRI gadolinium-based contrast agents. Radiologists beware!" Ann Pharm Fr 67(5): 335-339.

Gray, M. L., D. Burstein, Y. J. Kim and A. Maroudas (2008). "2007 Elizabeth Winston Lanier Award Winner. Magnetic resonance imaging of cartilage glycosaminoglycan: basic principles, imaging technique, and clinical applications." J Orthop Res 26(3): 281-291.

Green, R., G. Cutter, M. Friendly and I. Kister (2017). "Which symptoms contribute the most to patients' perception of health in multiple sclerosis?" Mult Scler J Exp Transl Clin 3(3): 2055217317728301. 
Gulani, V., F. Calamante, F. G. Shellock, E. Kanal, S. B. Reeder and M. International Society for Magnetic Resonance in (2017). "Gadolinium deposition in the brain: summary of evidence and recommendations." Lancet Neurol 16(7): 564-570.

Hao, D., T. Ai, F. Goerner, X. Hu, V. M. Runge and M. Tweedle (2012). "MRI contrast agents: basic chemistry and safety." J Magn Reson Imaging 36(5): 1060-1071.

Hunt, C. H., R. P. Hartman and G. K. Hesley (2009). "Frequency and severity of adverse effects of iodinated and gadolinium contrast materials: retrospective review of 456,930 doses." AJR Am J Roentgenol 193(4): 1124-1127.

Ibrahim, M. A. and A. B. Dublin (2018). Magnetic Resonance Imaging (MRI), Gadolinium. StatPearls. Treasure Island (FL).

Ichikawa, S., U. Motosugi, Y. Omiya and H. Onishi (2017). "Contrast Agent-Induced High Signal Intensity in Dentate Nucleus on Unenhanced T1-Weighted Images: Comparison of Gadodiamide and Gadoxetic Acid." Invest Radiol 52(7): 389-395.

Izquierdo, G. (2017). "Multiple sclerosis symptoms and spasticity management: new data." Neurodegener Dis Manag 7(6s): 7-11.

Jung, J. W., H. R. Kang, M. H. Kim, W. Lee, K. U. Min, M. H. Han and S. H. Cho (2012). "Immediate hypersensitivity reaction to gadolinium-based MR contrast media." Radiology 264(2): 414-422.

Kaminska, J., O. M. Koper, K. Piechal and H. Kemona (2017). "Multiple sclerosis etiology and diagnostic potential." Postepy Hig Med Dosw (Online) 71(0): 551-563.

Kanda, T., K. Ishii, H. Kawaguchi, K. Kitajima and D. Takenaka (2014). "High signal intensity in the dentate nucleus and globus pallidus on unenhanced T1-weighted MR images: relationship with increasing cumulative dose of a gadolinium-based contrast material." Radiology 270(3): 834-841.

Kaunzner, U. W. and S. A. Gauthier (2017). "MRI in the assessment and monitoring of multiple sclerosis: an update on best practice." Ther Adv Neurol Disord 10(6): 247-261.

Krebs, N., C. Langkammer, W. Goessler, S. Ropele, F. Fazekas, K. Yen and E. Scheurer (2014). "Assessment of trace elements in human brain using inductively coupled plasma mass spectrometry." J Trace Elem Med Biol 28(1): 1-7.

Kurtzke, J. F. (2005). "Epidemiology and etiology of multiple sclerosis." Phys Med Rehabil Clin N Am 16(2): 327-349.

Loken-Amsrud, K. I., A. Lossius, O. Torkildsen and T. Holmoy (2015). "Impact of the environment on multiple sclerosis." Tidsskr Nor Laegeforen 135(9): 856-860.

Lublin, F. D., S. C. Reingold, J. A. Cohen, G. R. Cutter, P. S. Sorensen, A. J. Thompson, J. S. Wolinsky, L. J. Balcer, B. Banwell, F. Barkhof, B. Bebo, Jr., P. A. Calabresi, M. Clanet, G. Comi, R. J. Fox, M. S. Freedman, A. D. Goodman, M. Inglese, L. Kappos, B. C. Kieseier, J. A. Lincoln, C. Lubetzki, A. E. Miller, X. Montalban, P. W. O'Connor, J. Petkau, C. Pozzilli, R. A. Rudick, M. P. Sormani, O. Stuve, E. Waubant and C. H. Polman (2014). "Defining the clinical course of multiple sclerosis: the 2013 revisions." Neurology 83(3): 278-286.

Martinez-Criado, G., J. Villanova, R. Tucoulou, D. Salomon, J. P. Suuronen, S. Laboure, C. Guilloud, V. Valls, R. Barrett, E. Gagliardini, Y. Dabin, R. Baker, S. Bohic, C. Cohen and J. Morse (2016). "ID16B: a hard X-ray nanoprobe beamline at the ESRF for nano-analysis." Journal of Synchrotron Radiation 23: 344-352.

McDonald, R. J., J. S. McDonald, D. F. Kallmes, M. E. Jentoft, D. L. Murray, K. R. Thielen, E. E. Williamson and L. J. Eckel (2015). "Intracranial Gadolinium Deposition after Contrast-enhanced MR Imaging." Radiology 275(3): 772-782.

McGowan, J. C. (2008). "Basic principles of magnetic resonance imaging." Neuroimaging Clin N Am 18(4): 623-636, $\mathrm{x}$. 
McNamara, C. and G. Rahmani (2018). "Gena Norris and gadolinium deposition diseasethe impact of celebrity health disclosure on public awareness." Magn Reson Med 80(4): 12771278.

Mechelli, R., V. Annibali, G. Ristori, D. Vittori, G. Coarelli and M. Salvetti (2010). "Multiple sclerosis etiology: beyond genes and environment." Expert Rev Clin Immunol 6(3): 481-490.

Miller, D. H., R. I. Grossman, S. C. Reingold and H. F. McFarland (1998). "The role of magnetic resonance techniques in understanding and managing multiple sclerosis." Brain $\mathbf{1 2 1}$ ( Pt 1): 3-24.

Mittal, M., K. Kumar, D. Anghore and R. K. Rawal (2017). "ICP-MS: Analytical Method for Identification and Detection of Elemental Impurities." Curr Drug Discov Technol 14(2): 106120.

Morcos, S. K. (2008). "Extracellular gadolinium contrast agents: differences in stability." Eur J Radiol 66(2): 175-179.

Murata, N., L. F. Gonzalez-Cuyar, K. Murata, C. Fligner, R. Dills, D. Hippe and K. R. Maravilla (2016). "Macrocyclic and Other Non-Group 1 Gadolinium Contrast Agents Deposit Low Levels of Gadolinium in Brain and Bone Tissue: Preliminary Results From 9 Patients With Normal Renal Function." Invest Radiol 51(7): 447-453.

Panigrahy, A., M. Borzage and S. Bluml (2010). "Basic principles and concepts underlying recent advances in magnetic resonance imaging of the developing brain." Semin Perinatol 34(1): 3-19.

Pooley, R. A. (2005). "AAPM/RSNA physics tutorial for residents: fundamental physics of MR imaging." Radiographics 25(4): 1087-1099.

Prince, M. R., H. Zhang, Z. Zou, R. B. Staron and P. W. Brill (2011). "Incidence of immediate gadolinium contrast media reactions." AJR Am J Roentgenol 196(2): W138-143.

Rangachari, M. and V. K. Kuchroo (2013). "Using EAE to better understand principles of immune function and autoimmune pathology." J Autoimmun 45: 31-39.

Robert, P., S. Fingerhut, C. Factor, V. Vives, J. Letien, M. Sperling, M. Rasschaert, R. Santus, S. Ballet, J. M. Idee, C. Corot and U. Karst (2018). "One-year Retention of Gadolinium in the Brain: Comparison of Gadodiamide and Gadoterate Meglumine in a Rodent Model." Radiology 288(2): 424-433.

Robert, P., S. Lehericy, S. Grand, X. Violas, N. Fretellier, J. M. Idee, S. Ballet and C. Corot (2015). "T1-Weighted Hypersignal in the Deep Cerebellar Nuclei After Repeated Administrations of Gadolinium-Based Contrast Agents in Healthy Rats: Difference Between Linear and Macrocyclic Agents." Invest Radiol 50(8): 473-480.

Robinson, A. P., C. T. Harp, A. Noronha and S. D. Miller (2014). "The experimental autoimmune encephalomyelitis (EAE) model of MS: utility for understanding disease pathophysiology and treatment." Handb Clin Neurol 122: 173-189.

Rodushkin, I., E. Engstrom and D. C. Baxter (2013). "Isotopic analyses by ICP-MS in clinical samples." Anal Bioanal Chem 405(9): 2785-2797.

Sanyal, S., P. Marckmann, S. Scherer and J. L. Abraham (2011). "Multiorgan gadolinium (Gd) deposition and fibrosis in a patient with nephrogenic systemic fibrosis--an autopsy-based review." Nephrol Dial Transplant 26(11): 3616-3626.

Sato, T., K. Ito, T. Tamada, A. Kanki, S. Watanabe, H. Nishimura, D. Tanimoto, H. Higashi and A. Yamamoto (2013). "Tissue gadolinium deposition in renally impaired rats exposed to different gadolinium-based MRI contrast agents: evaluation with inductively coupled plasma mass spectrometry (ICP-MS)." Magn Reson Imaging 31(8): 1412-1417.

Sato, T., T. Tamada, S. Watanabe, H. Nishimura, A. Kanki, Y. Noda, A. Higaki, A. Yamamoto and K. Ito (2015). "Tissue gadolinium deposition in hepatorenally impaired rats 
exposed to Gd-EOB-DTPA: evaluation with inductively coupled plasma mass spectrometry (ICP-MS)." Radiol Med 120(6): 557-562.

Semelka, R. C., J. Ramalho, A. Vakharia, M. AlObaidy, L. M. Burke, M. Jay and M. Ramalho (2016). "Gadolinium deposition disease: Initial description of a disease that has been around for a while." Magn Reson Imaging 34(10): 1383-1390.

Semelka, R. C., M. Ramalho, M. Jay, L. Hickey and J. Hickey (2018). "Intravenous Calcium-/Zinc-Diethylene Triamine Penta-Acetic Acid in Patients With Presumed Gadolinium Deposition Disease: A Preliminary Report on 25 Patients." Invest Radiol 53(6): 373-379.

Sintzel, M. B., M. Rametta and A. T. Reder (2018). "Vitamin D and Multiple Sclerosis: A Comprehensive Review." Neurol Ther 7(1): 59-85.

Steiner, I., P. Nisipianu and I. Wirguin (2001). "Infection and the etiology and pathogenesis of multiple sclerosis." Curr Neurol Neurosci Rep 1(3): 271-276.

Stikova, E. (2012). "Magnetic resonance imaging safety: principles and guidelines." Prilozi 33(1): 441-472.

Stojanov, D. A., A. Aracki-Trenkic, S. Vojinovic, D. Benedeto-Stojanov and S. Ljubisavljevic (2016). "Increasing signal intensity within the dentate nucleus and globus pallidus on unenhanced T1W magnetic resonance images in patients with relapsing-remitting multiple sclerosis: correlation with cumulative dose of a macrocyclic gadolinium-based contrast agent, gadobutrol." Eur Radiol 26(3): 807-815.

Stromnes, I. M. and J. M. Goverman (2006). "Active induction of experimental allergic encephalomyelitis." Nat Protoc 1(4): 1810-1819.

Tedeschi, E., F. Caranci, F. Giordano, V. Angelini, S. Cocozza and A. Brunetti (2017). "Gadolinium retention in the body: what we know and what we can do." Radiol Med 122(8): 589-600.

Telgmann, L., H. Faber, S. Jahn, D. Melles, H. Simon, M. Sperling and U. Karst (2012). "Identification and quantification of potential metabolites of Gd-based contrast agents by electrochemistry/separations/mass spectrometry." J Chromatogr A 1240: 147-155.

Thakral, C. and J. L. Abraham (2007). "Automated scanning electron microscopy and x-ray microanalysis for in situ quantification of gadolinium deposits in skin." J Electron Microsc (Tokyo) 56(5): 181-187.

Thompson, A. J., B. L. Banwell, F. Barkhof, W. M. Carroll, T. Coetzee, G. Comi, J. Correale, F. Fazekas, M. Filippi, M. S. Freedman, K. Fujihara, S. L. Galetta, H. P. Hartung, L. Kappos, F. D. Lublin, R. A. Marrie, A. E. Miller, D. H. Miller, X. Montalban, E. M. Mowry, P. S. Sorensen, M. Tintore, A. L. Traboulsee, M. Trojano, B. M. J. Uitdehaag, S. Vukusic, E. Waubant, B. G. Weinshenker, S. C. Reingold and J. A. Cohen (2018). "Diagnosis of multiple sclerosis: 2017 revisions of the McDonald criteria." Lancet Neurol 17(2): 162-173.

Tommasin, S., C. Gianni, L. De Giglio and P. Pantano (2017). "Neuroimaging techniques to assess inflammation in Multiple Sclerosis." Neuroscience.

Tourbah, A. and I. Berry (2000). "[Magnetic resonance imaging in multiple sclerosis]." Pathol Biol (Paris) 48(2): 151-161.

van de Looij, Y., L. Vasung, S. V. Sizonenko and P. S. Huppi (2014). "MRI of animal models of developmental disorders and translation to human imaging." Curr Opin Neurol 27(2): 157-167.

Weissert, R. (2013). "The immune pathogenesis of multiple sclerosis." J Neuroimmune Pharmacol 8(4): 857-866.

White, G. W., W. A. Gibby and M. F. Tweedle (2006). "Comparison of Gd(DTPA-BMA) (Omniscan) versus Gd(HP-DO3A) (ProHance) relative to gadolinium retention in human bone tissue by inductively coupled plasma mass spectroscopy." Invest Radiol 41(3): 272-278. 
Xia, D., R. L. Davis, J. A. Crawford and J. L. Abraham (2010). "Gadolinium released from MR contrast agents is deposited in brain tumors: in situ demonstration using scanning electron microscopy with energy dispersive X-ray spectroscopy." Acta Radiol 51(10): 1126-1136. 


\section{Eidesstattliche Versicherung (Affidavit)}

I, Shuangqing Wang, certify under penalty of perjury by my own signature that I have submitted the thesis on the topic: [Increased Retention of Gadolinium in the Inflamed Brain after repeated administration of gadopentetate dimeglumine: A Proof-ofConcept Study in Mice Combining ICP-MS and Micro- and Nano-SR-XRF]. I wrote this thesis independently and without assistance from third parties, I used no other aids than the listed sources and resources.

All points based literally or in spirit on publications or presentations of other authors are, such as, in proper citations (see "uniform requirements for manuscripts (URM)" the ICMJE www.icmje.org) indicated. The sections on methodology (in particular practical work, laboratory requirements, statistical procession) and results (in particular images, graphics and tables) correspond to the URM (s.o) and are answered by me. My contributions in the publication for this thesis correspond to those that are specific in the following joint declaration with the responsible person and supervisor. All publications resulting from this thesis, I am solely responsible.

The importance of this affidavit and the criminal consequences of a false affidavit (section 156,161 of the Criminal Code) are known to me and I understand the rights and responsibilities started therein.

Date: Shuangqing Wang 


\section{Ausführliche Anteilserklärung an der erfolgten Publikation}

Publication: Shuangqing Wang", Bernhard Hesse", Marco Roman, Deborah Stier, Hiram Castillo-Michel, Marine Cotte, Jussi-Petteri Suuronen, Adrien Lagrange, Helena Radbruch, Friedemann Paul, Matthias Taupitz, Eyk Schellenberger, Ingolf Sack, Carmen Infante-Duarte. Increased Retention of Gadolinium in the Inflamed Brain after repeated administration of gadopentetate dimeglumine: A Proof-of-Concept Study in Mice Combining ICP-MS and Micro- and Nano-SR-XRF.

\# shared first authorship

Shuangqing Wang contributed to the concept and study protocol of all experiments. She induced $E A E$, weighted and scored the EAE animals, and administrated repeated gadolinium-based contrast agent injections through the mouse tail vein. Moreover, she scanned the mouse 7-Tesla MRI. In addition, she sacrificed the healthy controls and EAE mice to obtain brain tissue and prepared the frozen tissue to inductively coupled plasma mass spectrometry (ICP-MS), as well as fixed tissue slices to histology and micro- and nano-synchrotron X-ray fluorescence microscopy (SR-XRF). Furthermore, she went to ESRF to image the retention of gadolinium using SR-XRF, with the help of Dr. Bernhard Hesse. Afterwards, she analyzed the respective results from her experiments, did the statistical analysis and prepared the figures for the paper. Finally, she prepared and revised together with Dr. Hesse and Dr. Infante-Duarte the manuscript. This publication has only been used for her thesis.

Unterschrift, Datum und Stempel der betreuenden Hochschullehrerin: PD. Dr. Carmen Infante-Duarte

Unterschrift der Doktorandin: Shuangqing Wang 


\section{Auszug aus der Journal Summary List}

Journal Data Filtered By: Selected JCR Year: 2017 Selected Editions: SCIE,SSCI Selected Categories: "RADIOLOGY, NUCLEAR MEDICINE and MEDICAL

IMAGING" Selected Category Scheme: WoS

Gesamtanzahl: 128 Journale

\begin{tabular}{|c|c|c|c|c|}
\hline Rank & Full Journal Title & Total Cites & $\begin{array}{l}\text { Journal Impact } \\
\text { Factor }\end{array}$ & Eigenfactor Score \\
\hline 1 & JACC-Cardiovascular Imaging & 8,104 & 10.247 & 0.026360 \\
\hline 2 & $\begin{array}{r}\text { European Heart Journal- } \\
\text { Cardiovascular Imaging }\end{array}$ & 4,630 & 8.336 & 0.020640 \\
\hline 3 & $\begin{array}{r}\text { EUROPEAN JOURNAL OF } \\
\text { NUCLEAR MEDICINE AND } \\
\text { MOLECULAR IMAGING }\end{array}$ & 14,983 & 7.704 & 0.024870 \\
\hline 4 & RADIOLOGY & 54,109 & 7.469 & 0.063710 \\
\hline 5 & $\begin{array}{r}\text { JOURNAL OF NUCLEAR } \\
\text { MEDICINE } \\
\end{array}$ & 27,101 & 7.439 & 0.037560 \\
\hline 6 & $\begin{array}{r}\text { CLINICAL NUCLEAR } \\
\text { MEDICINE } \\
\end{array}$ & 4,756 & 6.281 & 0.006950 \\
\hline 7 & INVESTIGATIVE RADIOLOGY & 6,486 & 6.224 & 0.012410 \\
\hline 8 & $\begin{array}{r}\text { Circulation-Cardiovascular } \\
\text { Imaging }\end{array}$ & 5,438 & 6.221 & 0.020160 \\
\hline 9 & $\begin{array}{r}\text { IEEE TRANSACTIONS ON } \\
\text { MEDICAL IMAGING }\end{array}$ & 17,837 & 6.131 & 0.024200 \\
\hline 10 & $\begin{array}{r}\text { ULTRASOUND IN } \\
\text { OBSTETRICS \& GYNECOLOGY }\end{array}$ & 12,420 & 5.654 & 0.018820 \\
\hline 11 & $\begin{array}{r}\text { INTERNATIONAL JOURNAL } \\
\text { OF RADIATION ONCOLOGY } \\
\text { BIOLOGY PHYSICS }\end{array}$ & 46,595 & 5.554 & 0.055060 \\
\hline 12 & $\begin{array}{r}\text { JOURNAL OF } \\
\text { CARDIOVASCULAR } \\
\text { MAGNETIC RESONANCE }\end{array}$ & 4,918 & 5.457 & 0.013530 \\
\hline 13 & NEUROIMAGE & 92,719 & 5.426 & 0.152610 \\
\hline 14 & MEDICAL IMAGE ANALYSIS & 6,383 & 5.356 & 0.011900 \\
\hline 15 & $\begin{array}{r}\text { RADIOTHERAPY AND } \\
\text { ONCOLOGY }\end{array}$ & 17,184 & 4.942 & 0.027840 \\
\hline 16 & HUMAN BRAIN MAPPING & 20,334 & 4.927 & 0.042810 \\
\hline 17 & $\begin{array}{r}\text { SEMINARS IN NUCLEAR } \\
\text { MEDICINE }\end{array}$ & 2,285 & 4.558 & 0.002990 \\
\hline 18 & $\begin{array}{r}\text { ULTRASCHALL IN DER } \\
\text { MEDIZIN }\end{array}$ & 2,201 & 4.389 & 0.004310 \\
\hline 19 & $\begin{array}{r}\text { MAGNETIC RESONANCE IN } \\
\text { MEDICINE }\end{array}$ & 31,440 & 4.082 & 0.034130 \\
\hline 20 & EUROPEAN RADIOLOGY & 18,615 & 4.027 & 0.034120 \\
\hline 20 & $\begin{array}{r}\text { SEMINARS IN RADIATION } \\
\text { ONCOLOGY }\end{array}$ & 2,480 & 4.027 & 0.003620 \\
\hline 22 & $\begin{array}{r}\text { JOURNAL OF NUCLEAR } \\
\text { CARDIOLOGY }\end{array}$ & 3,508 & 3.847 & 0.004120 \\
\hline 23 & $\begin{array}{r}\text { AMERICAN JOURNAL OF } \\
\text { NEURORADIOLOGY }\end{array}$ & 22,667 & 3.653 & 0.029840 \\
\hline 24 & $\begin{array}{r}\text { JOURNAL OF MAGNETIC } \\
\text { RESONANCE IMAGING }\end{array}$ & 16,398 & 3.612 & 0.027440 \\
\hline 25 & $\begin{array}{r}\text { MOLECULAR IMAGING AND } \\
\text { BIOLOGY }\end{array}$ & 2,415 & 3.608 & 0.005480 \\
\hline
\end{tabular}




\section{The published paper}

Increased Retention of Gadolinium in the Inflamed Brain after repeated administration of gadopentetate dimeglumine: A Proof-of-Concept Study in Mice Combining ICP-MS and Micro- and Nano-SR-XRF.

Shuangqing Wang\#, Bernhard Hesse", Marco Roman, Deborah Stier, Hiram CastilloMichel, Marine Cotte, Jussi-Petteri Suuronen, Adrien Lagrange, Helena Radbruch, Friedemann Paul, Matthias Taupitz, Eyk Schellenberger, Ingolf Sack, Carmen InfanteDuarte*.

Shuangqing Wang", Bernhard Hesse ${ }^{\#}$, Marco Roman, Deborah Stier, Hiram Castillo-Michel, Marine Cotte, Jussi-Petteri Suuronen, Adrien Lagrange, Helena Radbruch, Friedemann Paul, Matthias Taupitz, Eyk Schellenberger, Ingolf Sack, Carmen Infante-Duarte*. Increased Retention of Gadolinium in the Inflamed Brain after repeated administration of gadopentetate dimeglumine: A Proof-of-Concept Study in Mice Combining ICP-MS and Micro- and Nano-SR-XRF.Investigative Radiology: October 2019 - Volume 54 - Issue 10 - p 617-626 DOI: 10.1097/RLI.0000000000000571 


\section{Curriculum vitae}

My curriculum vitae does not appear in the electronic version of my paper for reasons of data protection. 


\section{Publication list}

1. Shuangqing Wang\#; Bernhard Hesse\#; Marco Roman; Deborah Stier; Hiram Castillo-Michel; Marine Cotte; Jussi-Petteri Suuronen; Adrien Lagrange; Helena Radbruch; Friedemann Paul; Matthias Taupitz; Eyk Schellenberger; Ingolf Sack; Carmen Infante-Duarte*; Increased Retention of Gadolinium in the Inflamed Brain After Repeated Administration of Gadopentetate Dimeglumine: A Proof-of-Concept Study in Mice Combining ICP-MS and Micro- and Nano-SR-XRF, Investigative Radiology, 2019, 54(10): 617-626.

2. Jing Guo*; Gergely Bertalan; David Meierhofer; Charlotte Klein; Stefanie Schreyer; Barbara Steiner; Shuangqing Wang; Rafaela Vieira da Silva; Carmen Infante-Duarte; Stefan Koch; Philipp Boehm-Sturm; Jürgen Braun; Ingolf Sack*; Brain maturation is associated with increasing tissue stiffness and decreasing tissue fluidity, Acta Biomaterialia, 2019, 99: 433-442.

3. Shuangqing Wang\#; Jason M. Millward\#; Laura Hanke-Vela\#; Bimala Malla; Kjara

Pilch; Ana Gil-Infante; Sonia Waiczies; Susanne Mueller; Philipp Boehm-Sturm; Jing Guo; Ingolf Sack; Carmen Infante-Duarte; MR Elastography-Based Assessment of Matrix Remodeling at Lesion Sites Associated With Clinical Severity in a Model of Multiple Sclerosis, Frontiers in Neurology, 2020, 10(1382). 


\section{Acknowledgements}

I would like to express the deepest appreciation to my supervisor PD. Dr. Carmen Infante-Duarte who supported me during the whole process of my doctoral thesis and introduced me to the field of neuroimmunology. I am very grateful for her friendly behavior and great help. I was a newborn in neuroimmunology research field and keeps growing these years under her supervising. Without her guidance and persist help this thesis would not have been possible.

I would like to thank Prof. Ingolf Sack, who introduced me to the field of Neuroimaging and supported me the magnetic resonance imaging techniques.

I would like to thank Dr. Bernhard Hesse to prepare the preliminary ESRF work and image the SR-XRF maps.

In addition, I thank Dr. Jing Guo, Dr. Jason Millward and Dr. Philipp Böhm-Sturm for sharing their knowledge and technical support.

My thanks and appreciations also go to my technician (Dipl. Biol. Natalie Asselborn), and all other laboratory members (Silvina Romero Suárez, Bimala Mala, Juliana Campo Garcia, Alba Del Rio Serrato, Rafaela Vieira da Silva, et al.) and people who have willingly helped me out with their abilities.

Finally, I would like to thank my husband (Mr. Yue Zhu), my parents and my friends who keep me company on long walks. 